\title{
Constructing Scenarios' Network-of-Flight Conflict in Approach of Intersecting Runway
}

\author{
Ming Cheng $(\mathbb{D}$, Yixuan Li, and Xiaolian Han \\ College of Safety Science and Engineering, Civil Aviation University of China, Tianjin 300300, China \\ Correspondence should be addressed to Ming Cheng; figocm@163.com
}

Received 25 March 2021; Accepted 19 May 2021; Published 26 May 2021

Academic Editor: Massimiliano Zanin

Copyright ( $\odot 2021$ Ming Cheng et al. This is an open access article distributed under the Creative Commons Attribution License, which permits unrestricted use, distribution, and reproduction in any medium, provided the original work is properly cited.

\begin{abstract}
For studying the mechanism of flight conflict in approach of the intersecting runway, this paper applies the case study, scenario construction, and complex network, analyzes the operational risks of the intersecting runway, and researches the general rule of flight conflict. We constructed a network model of scenario evolution of flight conflict with selecting Beijing Daxing International Airport as the research object, which included 169 nodes and 263 edges. It proposed path evolution and verified the effectiveness of this network. We analyzed the degree centrality, median centrality, and closeness centrality of the network, and the results showed that the comprehensive value of 5 nodes is high, including go-around (V2), conflict resolution (C22), the warning light of aft cargo dJor was extinguished (F12), suspend subsequent take-off operations (F5), and keeping visual flying (C26). The results show that this method provides a new research way for the control strategy of chain breakage and the mechanism of scenario evolution of flight conflict.
\end{abstract}

\section{Introduction}

In recent years, in order to cope with the shortage of airport runway capacity in the development of civil aviation industry of China, airports are being rebuilt and expanded all over the country, which is a project with huge demands on land resources and environment. The airport with the intersecting runway has many advantages. On the one hand, it can adapt to the change of wind direction, realize omnidirectional take-off and landing, improve the efficiency and safety of the runway operation, and increase the flow. On the other hand, land resources can be greatly saved. The airports using the intersecting runway is becoming a superlarge and large airports, for example, Beijing Daxing International Airport [1], which operated in 2019.

There has been rich experience in the operation of the parallel runway in China. In 2005, Beijing Capital International Airport was the first airport in China to implement the independent operation of two runways. At the same time, the Civil Aviation Administration of China has continuously released the operation rules for multiple runways, such as CCAR-98TM [2] and CCAR93TM-R2 [3]. However, serious flight conflicts still occur in the operation of parallel runways in China. For example, the "10.11" flight conflict (serious accident) sign occurred in Shanghai Hongqiao Airport in 2016 [4].

\section{Research Actuality}

Because flight conflict is the direct cause of the plane crash [5], the research on the intersecting runway is relatively early abroad; most of the work progress to the prediction and prevention of the conflict stage, whose content involves the ground early warning system, the pilot alarm information, intersecting runway take-off location identification system, take-off and landing aircraft separation operation [6-8], etc.

However, due to the fact that the intersecting runway operation mode has not been officially used in China, current studies still focus on the wake interval, runway capacity, flight data analysis [9-11], and other related issues. The research in this area is relatively rare. In the relevant research on flight conflict, domestic scholars mostly take parallel runway as the basis and focus on conflict hotspot identification and the establishment and solution of the relief model [12-14]. 
Complex network has been applied to the risk scenarios' evolution process of the deep-water drilling platform [15] and amphibious seaplanes [16] and achieved remarkable results. At the same time, many hot problems in the field of civil aviation also applied to the single-layer and multi-layer complex network, such as the route network [17], the flight delays [18], traffic distribution strategy [19], and security vulnerability analysis [20], based on the performance of navigation $(\mathrm{PBN})$ [21].

The research actuality at home and abroad is supplemented and modified as follows: at present, many research studies on the prediction and prevention of aviation safety incidents rely on aviation safety incident reports, but most of the reports have problems such as large content and nonstandard language and writing style [22]. Therefore, it is vital to accurately identify why these incidents occurred in the aviation safety incident report [23]. Xu et al. studied Natural Language Process (NLP), text mining techniques, machine learning, and other aspects, which effectively improved the accuracy of information processing $[24,25]$.

At present, there are relatively few studies on the combination of the operation mode of the intersecting runway and the scenarios' evolution of flight conflict. In view of the actual operational requirements and potential safety problems of airports with superlarge intersecting runway in China, this paper adopts complex network theory and scenario analysis method to conduct scenario evolution and risk analysis of flight conflict of the intersecting runway, in order to explore a new way of describing and analyzing flight conflict risk.

\section{Construction of Method and Model}

\subsection{Theoretical Method}

3.1.1. Construction of Scenario Theory. A scenario is a collection of a large number of similar events and various risks that may occur in the future $[26,27]$. Scenario elements are usually analyzed from three dimensions of disaster body, disaster-resistant body, and disaster body [28]. Situational elements are the key factors of situational construction, which can reflect the development state and trend of events.

3.1.2. Complex Network Theory. Qian Xuesen defined that the complex network is the network with a part or all of the properties of self-organization, self-similarity, attractor, small world, and scale-free [29]. Based on system theory, graph theory, and statistical theory, the complex network can represent intuitively connectivity between system structures by establishing accident scenarios [30]. The complex network is described by a weighted directed acyclic connected graph $G=(V, L, W)$ of the sparse matrix, which is suitable for the study of accidents with complex accident mechanism, numerous risk factors, and risk factors with complex relationships and complex accident models' components.

(1) The node degrees

Node degree is the set of the input degree and exit degree of the node and the number of edges connected by nodes. The degree of node $t$ is denoted as

$$
k_{t}=\sum_{s} a_{t s} .
$$

In the type, $k_{t}$ is the degree of the node and $a_{t s}$ is the number of edges connected between nodes $v_{t}$ and $v_{s}$. Node degrees can reflect the importance of nodes. The greater the degree of the node is, the more important the nodes in the network are.

(2) The degree centrality

The degree centrality of nodes is to measure how closely a node in the network is connected with all other nodes. The degree centrality of nodes is denoted as

$$
C_{D}\left(v_{t}\right)=\frac{\sum_{t=1}^{s} a_{t s}}{s-1} .
$$

In the type, $C_{D}\left(v_{t}\right)$ is the degree centrality of nodes and $a_{t s}$ is the number of edges connected between nodes $v_{t}$ and $v_{s}$ (excluding self-ring). The degree centrality of a node reflects the degree of association between a node and other nodes in the network. The greater the degree centrality of a node, the closer the connection between the node and other nodes.

(3) Median centrality

Median centrality of a node is the ratio of the number of shortest paths a node has passed to all shortest paths in the network. The median centrality of a node is noted as

$$
C_{B}\left(v_{t}\right)=\sum_{s \neq v \neq t \in V} \frac{\sigma_{s t}(v)}{\sigma_{s t}} .
$$

In the type, $C_{B}\left(v_{t}\right)$ is the median centrality of nodes and $\sigma_{s t}(v)$ is the number of shortest paths through nodes $v$. Median centrality of nodes is another index that reflects the importance of nodes in the network. The greater the median centrality of nodes, the higher the position of nodes in the network.

(4) Closeness centrality

The closeness centrality of a node is the ratio of the number of all nodes related to a node in the network to the number of all shortest paths passing through this node:

$$
C\left(v_{s}\right)=\frac{1}{\sum_{v_{s}} d\left(v_{s}, v_{t}\right)} .
$$

In the type, $C\left(v_{s}\right)$ is the closeness centrality of nodes and $d\left(v_{s}, v_{t}\right)$ is the distance between nodes $v_{s}$ and $v_{t}$. Closeness centrality of nodes is a parameter that measures the importance of nodes by the average length of shortest paths between nodes. The greater the proximity centrality of nodes is, the more important the nodes in the network are.

3.2. Analysis of Risk Characteristics of Intersecting Runway Operation. The flight conflicts of the intersecting runway 
have varied causes and complex evolvement process, which is suitable for using the complex network to study. The complex network is between the regular grid and random network. The nodes are connected into edges in a self-organizing way, and the initial event evolves into the final event through different paths. The evolution of the intersecting runway flight conflict scenario has the following characteristics.

3.2.1. Complexity. The risks of flying at low and medium altitudes, especially in tower control areas, eventually emerge in the operation. In the process of flight, facing the influence of turbulence, thunderstorm, wind shear, ice accumulation, and other bad weather, restrictions on airspace imposed by military aviation activities have randomness and variability, and aircraft and air traffic control equipment are prone to failure. These risk factors interact with each other in a complex way, projecting them into the network as nodes.

3.2.2. Small-World Character. The small world of the evolution of the risk of intersecting runway flight conflict is reflected in that, although there are many risk factors affecting flight conflict events, it can occur in a few short nodes between the initial event and the resulting event.

3.2.3. Scale-Free Features. The scale-free property of the complex network mainly describes the problem of the node degree. A few nodes in the network have a lot of connections, while most do not. In the evolution process of flight conflict scenarios for the intersecting runway, most risk factors revolve around the results of flight conflict and several major risk factors leading to flight conflict, such as aborted approach, go-around, re-approach, and so on, which reflect the scale-free characteristics in the evolution process.

3.2.4. Community Structure Characteristics. Intersecting runway flight conflict situation evolution concerns the four types of risk factors of Human, Machine, Ring, and Tube. The complex network provides a model that can show the interrelationships between each type of the risk factor and the interaggregation of related risk factors. Categorizing these risk factors, we can identify the commonalities of these risk factors and the relationships between each type of factor.

\subsection{Construction of Scenarios' Evolutionary Network Model of Flight Conflict in Approach Stage}

3.3.1. Identification of Operational Risk Factors for Airport with Intersecting Runway Configuration. This study was based on the real layout of the intersecting runway of Daxing Airport. Major operational risks in the approach phase are shown in Table 1.

3.3.2. Network Model Construction Procedures. The process of constructing the evolution network model of flight conflict scenarios in the approach stage of Daxing Airport's cross-runway is as follows:

(1) Data Processing. Collected and sorted out laws and regulations related to intersecting runway operation of civil aviation as well as relevant data of Daxing Airport's operating and natural environment; a total of 906 flight conflict incidents were collected and summarized from 2010 to 2019. The cases were divided into 6 categories, including aborted approach, rejected take-off, runway unusable, ground activities, unmanned aerial vehicles, and certain consequences.

(2) Case Study. We defined relevant risk factors that could lead to flight conflict as a keyword library, applied the Chinese Word Segmentation technology of Python ieba function library to extract the keywords in the event, and counted the frequency of statistical keyword, logical relationship, and other parameters, and the keyword library is modified by the results of the Chinese Word Segmentation technology to make it closer to the case contents.

(3) Construction of Scenario Group. Constructed the logical link between the keywords in taking a single case as a unit, extracted the safety risk factors, scenario description, scenarios' elements and nodes of flight conflict occurring during aircraft approach in the terminal area of the airport with the intersecting runway, and constructed the scenario group and evolution network

(4) The Construction of Complex Network. Sorted out the public node of different scenarios and plotted complex network diagrams for flight conflict scenarios in the intersecting runway terminal area of Daxing Airport.

(5) Analysis of Experimental Results. Calculated network parameters including node, edge, and weight and analyzed their influence on flight safety.

\section{The Empirical Analysis}

4.1. The Experimental Background. This paper is based on the actual layout of the intersecting runway of Daxing Airport and assumes that the flight conflict would occur after the $11 \mathrm{~L} / 29 \mathrm{R}$ runway was put into operation: the landing would be made on the $29 \mathrm{R}$ runway, the approaching aircraft would stop the approach and go-around, and its track would cross with the aircraft taking off and landing on other runways, resulting in flight conflict.

4.2. Complex Network Construction. The risk factors of the abort approach event case set, namely, nodes of the complex network, were extracted, including 37 nodes. The risk factors (nodes) of the abort approach scenario are shown in Table 2.

By sorting and screening invalid edges in the network (go-around $\longrightarrow$ abort approach), the obtained directed network graph contains 78 edges, as shown in Figure 1.

By the same token, the nodes of the other 5 cases were extracted and constructed to network. Because of the limit of 
TABLE 1: Operational risk.

\begin{tabular}{|c|c|c|}
\hline Risk category & Risk name & Risk description \\
\hline \multirow{4}{*}{ Flight risk } & TCAS warning & $\begin{array}{l}\text { Daxing Airport consists of four runways. The } 11 \mathrm{~L} / 29 \mathrm{R} \text { runway is an intersecting runway } \\
\text { located in the East. Due to different operation modes, it is easy to cause TCAS warning }\end{array}$ \\
\hline & Flight conflict & $\begin{array}{l}\text { There will be a potential flight conflict with the operation of landing on } 29 \mathrm{R} \text { runway: the plane } \\
\text { go-around track on 29R runway will cross with the tracks of the operating plane on the others } \\
\text { runways }\end{array}$ \\
\hline & $\begin{array}{l}\text { Under the minimum } \\
\text { interval }\end{array}$ & $\begin{array}{c}\text { When multiple runways approach and take off at the same time, it is easy to trigger alarm, and } \\
\text { there have been incidents that the approaching aircraft of adjacent runways under the } \\
\text { minimum interval }\end{array}$ \\
\hline & Wrong runway & $\begin{array}{l}\text { There is an air force airport runway on the west side, which is not used for civil aviation, but it } \\
\text { was easy to landed on the wrong runway and generate TCAS alarm }\end{array}$ \\
\hline \multirow{2}{*}{$\begin{array}{l}\text { Environmental } \\
\text { risk }\end{array}$} & Tailwind & $\begin{array}{l}\text { When the aircraft runs northward, it is easy to run tailwind in spring and summer, which } \\
\text { reduces the take-off and go-around performance of the aircraft }\end{array}$ \\
\hline & Unstable approach & $\begin{array}{l}\text { In the southward operation, due to the influence of terrain, it is easy to face turbulence, which } \\
\text { has great interference on the approach stability and flight parameters }\end{array}$ \\
\hline \multirow[b]{2}{*}{ Operation limit } & Forbidden zone & There are a lot of forbidden zones around Beijing \\
\hline & Secondary radar fault & $\begin{array}{l}\text { Taking off and landing aircraft without secondary radar transponders is prohibited in the } \\
\text { airport; when secondary radar transponders fail on the ground or in the air, restrictions are } \\
\text { formed }\end{array}$ \\
\hline
\end{tabular}

TABLE 2: Risk factors of the aborted approach scenario (nodes).

\begin{tabular}{lc}
\hline Numbers & Risk factors \\
\hline A1 & Abort approach \\
A2 & Wind shear \\
A3 & Turbulent flow \\
A4 & Go-around \\
A5 & Thunderstorm \\
A6 & Rainfall \\
A7 & Unable to see the runway \\
A8 & Excessive tailwind \\
A9 & Turbulence \\
A10 & Excessive gust \\
A11 & The control orders plane to slow down \\
A12 & Causes of runway configuration \\
A13 & Failed to get off the runway in time \\
A14 & Reapproach \\
A15 & Flap fault \\
A16 & Unable to see the front plane \\
A17 & Still has catch-up trend \\
A18 & Under the wake interval \\
A19 & Overweight \\
A20 & Continue to catch up with the front plane \\
A21 & Catch up with the front plane \\
A22 & Dissatisfaction landing interval \\
A23 & Bird strike \\
A24 & There is a trend of catching up \\
A25 & Unstable approach \\
A26 & Runway suspended \\
A27 & Bias navigation \\
A28 & Avoid \\
A29 & Crossing the runway waiting line \\
A30 & Conflict \\
A31 & Crosswind \\
A32 & TCAS warning \\
A33 & Conflict warning \\
A34 & PTCAS \\
A35 & Blind approach \\
A36 & F37 \\
- & Frost fog \\
\hline & \\
\hline
\end{tabular}

the space, it is not here. Sorted public nodes and used uniform labels to realize the connectivity of each network and get directed network diagram flight of conflict of Daxing Airport intersecting runway, which had a total of 169 nodes' risk factors (such as Table 3) and 263 sides (as shown in Figure 2).

According to Table 3 and Figure 2, the nodes V1-V30 are common nodes of all kinds of events, nodes A1-A21 represent the abort approach events, nodes B1-B16 represent runway unavailable events, nodes $\mathrm{C} 1-\mathrm{C} 34$ represent cause events that may cause certain consequence, nodes D1-D12 represent UAV events, nodes E1-E20 represent ground activity events, nodes F1-F36 represent rejected take-off type events. The nodes of all kinds of events are connected with each other through V1-V30 nodes, which constitute the flight conflict scenario evolution network model of Daxing Airport's intersecting runway.

4.3. Network Parameters. Table 4 shows model parameters of the flight conflict scenario evolution network model of Daxing Airport's intersecting runway.

Table 4 shows that the network density of the network is 0.009 , and the network density is low, indicating that the model network is relatively loose, the evolution of the risk event is less, and the relevance is general; the network is 1.556 , indicating that each node of the network is connected to 2 other nodes, which conforms to the small-world characteristics of the complex network. In the mean calculation method, the weight of each side will be defaulted to 1. If the weight is considered while calculating the node degree, it can be obtained that the average weight of the network is 20.337 , indicating that the degree of discrete of side weight distribution in the network is large [31].

The weights of some edges are large, some are small. Few nodes have a large number of connections, and most nodes are rare, reflecting the no-scale characteristics of the complex network. The average path length of the network is 


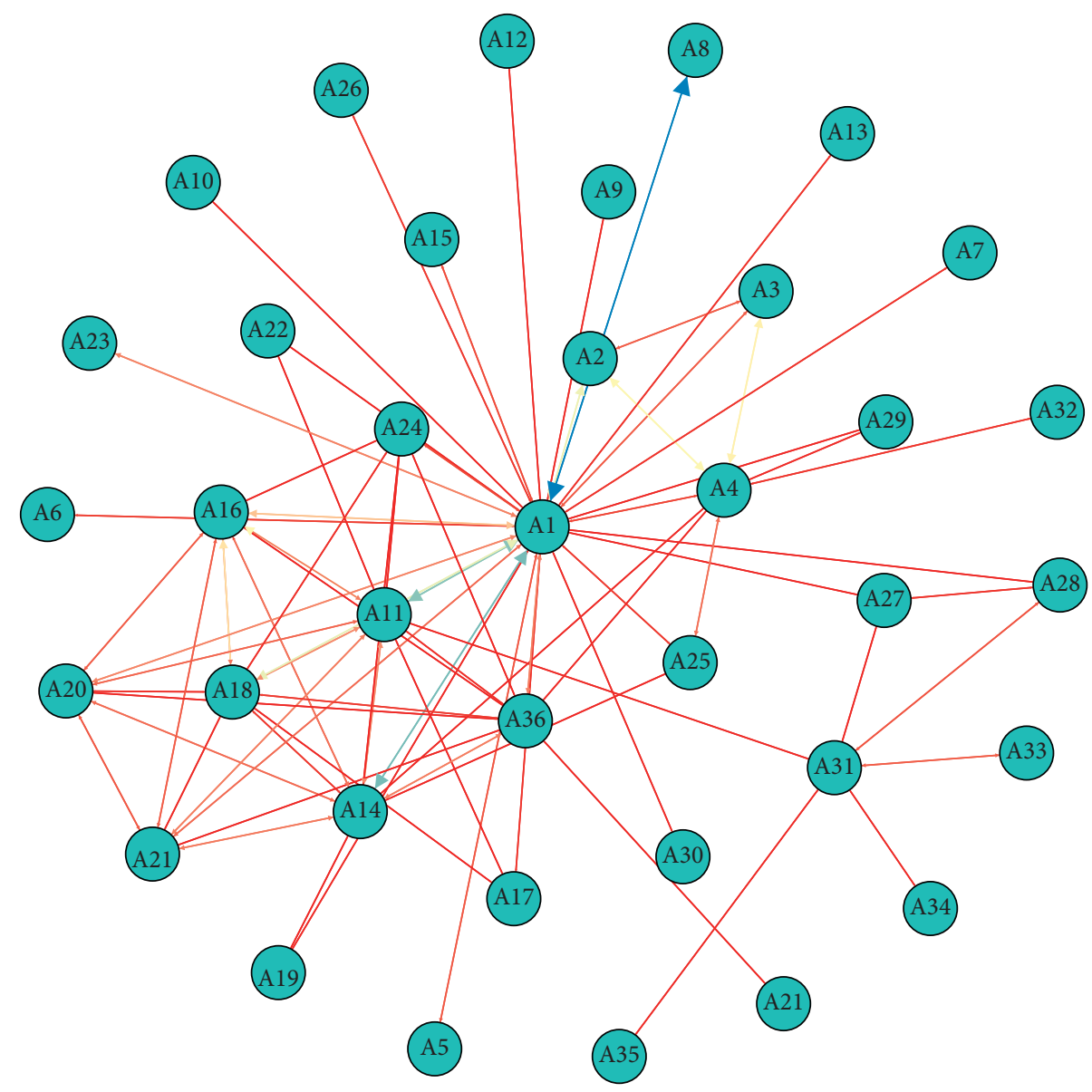

FIgURE 1: Directed network graph of the aborted approach cases.

3.143, indicating that each node can affect other nodes only through the average of 3.143 units. The network diameter of the network is 9, indicating that any of the nodes in the network may cause flight conflicts up to 9 steps. The average cluster coefficient is 0.097 , which reflects that the interaction between nodes is low.

\section{Experimental Results' Discussion}

5.1. Node Degree and Degree Distribution. Table 5 shows that, in the flight conflict scenario evolution network model of Daxing Airport's intersecting runway, for the degree, the degrees and in-degree of the node (V1) are max. The degrees (degree value 38) are max, indicating that it is the most important node in the network, and the in-degrees (degree value 32) are max, indicating that the risk factors leading to the suspension of approach are the most, and it is difficult to control. V1 is a key risk factor and one of the necessary conditions leading to flight conflict. The result is completely consistent with the actual situation.

In terms of out-degree, the controller makes notification (V18), blind approach (V16), and check (V19), which are the three nodes with the largest out-degree. V18 is a process event and not a risk factor, so it can be ignored here. V16 is a node describing the approach state, which is a risk factor, and its large degree indicates that it is more likely to cause subsequent risk events in the process of blind approach.

Nodes with higher degrees should be paid attention during the evolution of flight conflict scenarios at the Daxing Airport crossing runway.

5.2. Betweenness Centrality of Nodes. Table 6 shows that the betweenness centrality values of V19 and V1 are the largest, which indicates that the shortest paths V19 and V1 pass are the most, and V19 and V1 play the most important role in the risk transmission process of the whole network.

The analysis of the actual case shows that the factors causing V1 include the abnormal state of runway and all kinds of approach equipment. In this case, the controller will inform the relevant ground personnel to check and clear trouble at the first time, so the betweenness centrality value of V19 is the largest among all risk event nodes, which is completely in line with the reality.

V19 and V1 play an important role in the evolution of flight conflict scenarios on the intersecting runway.

5.3. Closeness Centrality of Nodes. The 12 nodes in Table 7 had the highest closeness centrality. The closeness centrality of nodes shows of the location of nodes in the network. The 
TABLE 3: Risk factors (nodes).

\begin{tabular}{|c|c|c|}
\hline Numbers & Risk factors & Degree \\
\hline V1 & Abort approach & 38 \\
\hline $\mathrm{V} 2$ & Go-around & 9 \\
\hline V3 & Rainfall & 2 \\
\hline $\mathrm{V} 4$ & Turbulence & 3 \\
\hline V5 & Reapproach & 13 \\
\hline V6 & Flap fault & 2 \\
\hline V7 & Bird strike & 3 \\
\hline V8 & Runway suspended & 7 \\
\hline V9 & Avoid & 5 \\
\hline V10 & Ground proximity warning & 3 \\
\hline V11 & Crossing the runway waiting line & 4 \\
\hline V12 & Conflict & 10 \\
\hline V13 & TCAS warning & 1 \\
\hline V14 & Conflict warning & 2 \\
\hline V15 & PTCAS & 1 \\
\hline V16 & Blind approach & 14 \\
\hline V17 & Waiting in place & 3 \\
\hline V18 & Controller briefing & 33 \\
\hline V19 & Inspect & 18 \\
\hline $\mathrm{V} 20$ & Safe landing & 11 \\
\hline $\mathrm{V} 21$ & Approach coordination & 3 \\
\hline $\mathrm{V} 22$ & Normal approach & 6 \\
\hline $\mathrm{V} 23$ & Continue approach & 5 \\
\hline V24 & Run off the runway & 9 \\
\hline $\mathrm{V} 25$ & Alarm elimination & 2 \\
\hline V26 & Suit of pavement & 3 \\
\hline V27 & Change runway to land & 4 \\
\hline V28 & Glide back & 25 \\
\hline V29 & Take-off interrupted & 21 \\
\hline V30 & Automatic pressurization system failure & 1 \\
\hline A1 & Wind shear & 3 \\
\hline $\mathrm{A} 2$ & Turbulent flow & 3 \\
\hline A3 & Thunderstorm & 1 \\
\hline A4 & Unable to see the runway & 1 \\
\hline A5 & Excessive tailwind & 1 \\
\hline A6 & Excessive gust & 1 \\
\hline A7 & Orders plane to slow down & 12 \\
\hline A8 & Causes of runway configuration & 1 \\
\hline A9 & Failed to get off the runway in time & 1 \\
\hline A10 & Unable to see the front plane & 9 \\
\hline A11 & Still has catch-up trend & 3 \\
\hline A12 & Under the wake interval & 9 \\
\hline A13 & Overweight & 2 \\
\hline A14 & Continue to catch up with the front plane & 7 \\
\hline A 15 & Catch up with the front plane & 7 \\
\hline A16 & Dissatisfaction landing interval & 2 \\
\hline A 17 & There is a trend of catching up & 6 \\
\hline A18 & Unstable approach & 3 \\
\hline A19 & Bias navigation & 3 \\
\hline A20 & Crosswind & 1 \\
\hline $\mathrm{A} 21$ & Frost fog & 1 \\
\hline $\mathrm{B} 1$ & Repair & 2 \\
\hline B2 & No foreign matter was found & 1 \\
\hline B3 & The equipment is normal & 3 \\
\hline B4 & Departure aircraft waiting & 1 \\
\hline B5 & The course signal is normal & 3 \\
\hline B6 & Confirm whether the blind drop signal is stable & 2 \\
\hline B7 & Course stability & 2 \\
\hline B8 & Fragments & 1 \\
\hline B9 & Plastic bag & 1 \\
\hline
\end{tabular}


TABle 3: Continued.

\begin{tabular}{|c|c|c|}
\hline Numbers & Risk factors & Degree \\
\hline $\mathrm{B} 10$ & Course signal instability & 3 \\
\hline B11 & Course instability & 5 \\
\hline $\mathrm{B} 12$ & The one minute vector line swings left and right & 3 \\
\hline B13 & The course signal is unstable & 2 \\
\hline B14 & Signal instability of glide path & 2 \\
\hline B15 & The radar signal swings left and right & 1 \\
\hline B16 & Radar track swing & 2 \\
\hline $\mathrm{C} 1$ & MSAW alarm & 1 \\
\hline $\mathrm{C} 2$ & Descent height & 2 \\
\hline $\mathrm{C} 3$ & Stop descent & 2 \\
\hline $\mathrm{C} 4$ & Alarm release & 1 \\
\hline $\mathrm{C} 5$ & Unidentified vehicle & 2 \\
\hline C6 & Controller call field service assistance handling & 2 \\
\hline $\mathrm{C} 7$ & Radio jamming channel & 2 \\
\hline $\mathrm{C} 8$ & Get off the runway & 1 \\
\hline C9 & Deviation taxiway & 2 \\
\hline $\mathrm{C} 10$ & Guided vehicle passes the waiting point without permission & 1 \\
\hline $\mathrm{C} 11$ & Runway intrusion warning & 2 \\
\hline $\mathrm{C} 12$ & Controller verification & 2 \\
\hline $\mathrm{C} 13$ & The guide car exits outside the waiting point & 1 \\
\hline $\mathrm{C} 14$ & Breaking the command height & 1 \\
\hline $\mathrm{C} 15$ & Keep going up & 2 \\
\hline $\mathrm{C} 16$ & Controller command descent & 2 \\
\hline $\mathrm{C} 17$ & The height setting is correct & 1 \\
\hline $\mathrm{C} 18$ & Flight procedure error & 1 \\
\hline $\mathrm{C} 19$ & Upwind not turning according to the procedure & 2 \\
\hline $\mathrm{C} 20$ & Deviation from procedure & 2 \\
\hline $\mathrm{C} 21$ & Rejoin the correct take-off procedure & 1 \\
\hline $\mathrm{C} 22$ & Conflict resolution & 6 \\
\hline $\mathrm{C} 23$ & No TCAS alarm & 1 \\
\hline $\mathrm{C} 24$ & Controller asked if it could be visualized & 2 \\
\hline $\mathrm{C} 25$ & Visualization & 2 \\
\hline $\mathrm{C} 26$ & Keep visualization & 2 \\
\hline $\mathrm{C} 27$ & Converging flight at the same altitude & 1 \\
\hline $\mathrm{C} 28$ & Converging flight & 2 \\
\hline $\mathrm{C} 29$ & Slow down & 1 \\
\hline $\mathrm{C} 30$ & Under the regular interval & 1 \\
\hline $\mathrm{C} 31$ & Waiting outside the runway & 1 \\
\hline $\mathrm{C} 32$ & Drive-bird car for road inspection & 1 \\
\hline $\mathrm{C} 33$ & Waiting on taxiway & 2 \\
\hline $\mathrm{C} 34$ & Delay & 1 \\
\hline D1 & Drone & 5 \\
\hline D2 & Tower verification to crew & 4 \\
\hline D3 & Not found by the crew & 5 \\
\hline $\mathrm{D} 4$ & The operation was not affected & 2 \\
\hline D5 & Departure aircraft affected & 1 \\
\hline D6 & Approach aircraft affected & 1 \\
\hline D7 & The moving direction is uncertain & 1 \\
\hline D8 & Balloon & 4 \\
\hline D9 & Crew visual balloon activity & 1 \\
\hline $\mathrm{D} 10$ & Kite & 1 \\
\hline D11 & Floater & 1 \\
\hline D12 & Laser irradiation & 1 \\
\hline E1 & Airforce activities & 1 \\
\hline $\mathrm{E} 2$ & Reasons for passengers & 1 \\
\hline E3 & Mechanical fault & 1 \\
\hline $\mathrm{E} 4$ & Aircraft fault & 1 \\
\hline E5 & Fuel leakage & 1 \\
\hline E6 & Pollute taxiway & 2 \\
\hline E7 & The reason of frontier defense & 1 \\
\hline
\end{tabular}


TABLE 3: Continued.

\begin{tabular}{|c|c|c|}
\hline Numbers & Risk factors & Degree \\
\hline E8 & Crew timeout & 1 \\
\hline E9 & The visual range of runway is lower than its landing standard & 1 \\
\hline E10 & Pavement icing & 1 \\
\hline E11 & Flight control system fault & 1 \\
\hline E12 & Weather radar fault & 1 \\
\hline E13 & Aircraft technical reasons & 1 \\
\hline E14 & Front wheel turning fault & 1 \\
\hline E15 & Engine core de-icing component fault & 1 \\
\hline E16 & Departure time limit & 1 \\
\hline E17 & There are approaching planes on final & 2 \\
\hline E18 & Oil replenishment & 1 \\
\hline E19 & Abnormal front tire pressure display & 1 \\
\hline E20 & Hit by a special vehicle & 1 \\
\hline $\mathrm{F} 1$ & No impact on runway & 1 \\
\hline F2 & The tower asked if there was any hydraulic oil leakage & 2 \\
\hline F3 & No hydraulic oil leakage & 2 \\
\hline F4 & Need rescue service & 2 \\
\hline F5 & Suspension of subsequent take-off activities & 2 \\
\hline F6 & Further confirm the fault information & 1 \\
\hline F7 & Apply for glide back & 2 \\
\hline F8 & Uncertain whether there is any abandoning and scattering objects & 2 \\
\hline F9 & No service is required & 1 \\
\hline F10 & Recovery of runway & 2 \\
\hline F11 & Coordination of relevant airport departments & 1 \\
\hline F12 & The rear cargo door warning light extinguish & 2 \\
\hline F13 & RebJoting & 2 \\
\hline F13 & The rear cargo door is closed & 1 \\
\hline F14 & The push back light is on at the same time & 2 \\
\hline F16 & The computer shows that the hydraulic pressure is low & 1 \\
\hline F17 & Lost GPS signal & 1 \\
\hline F18 & Rear gate light on & 1 \\
\hline F19 & Rear cargo door warning light on & 1 \\
\hline F20 & Rear passenger compartment gate warning light on & 1 \\
\hline $\mathrm{F} 21$ & Fire engine in place & 2 \\
\hline F21 & Warehouse fire & 1 \\
\hline F22 & Fire emergency & 2 \\
\hline F24 & There is no smoke or fire outside the engine room & 2 \\
\hline F25 & The fire engine taxied behind & 1 \\
\hline F26 & There is no abnormal phenomenon in the fire report & 1 \\
\hline F27 & Right engine fault & 1 \\
\hline F28 & Oil leakage may occur & 1 \\
\hline F29 & Hatch open & 1 \\
\hline F30 & Cockpit voice recorder fault & 1 \\
\hline F31 & Computer fault & 1 \\
\hline F32 & Configuration alert & 1 \\
\hline F33 & Take-off configuration alert & 1 \\
\hline F34 & Front door of engine room not opened & 1 \\
\hline F35 & Air-brake fault & 1 \\
\hline F36 & Left side engine fault & 1 \\
\hline- & - & - \\
\hline
\end{tabular}

closer the node is near the network center, the more important is the node.

Go-around (V2) and conflict resolution (C22) are the key risk factors related to the occurrence of flight conflict events at Daxing Airport, and their closeness centrality is high.

The warning light off (F12) of the rear cargo door and interphone card group channel (C7) are both related to equipment failure. The inspection (V19) node is the node with the greatest median centrality, while the equipment failure-related node is closely related to V19.

The description of deviation procedure $(\mathrm{C} 20)$ in the case is that the pilot did not operate according to the prescribed procedure to cause deviation procedure, which is a human factor. The whole process of flight conflict in actual operation cannot be separated from human behavior.

Suspend of subsequent take-off activities (F5), maintain visual (C26), stop descent (C3), controller verification (C12), 


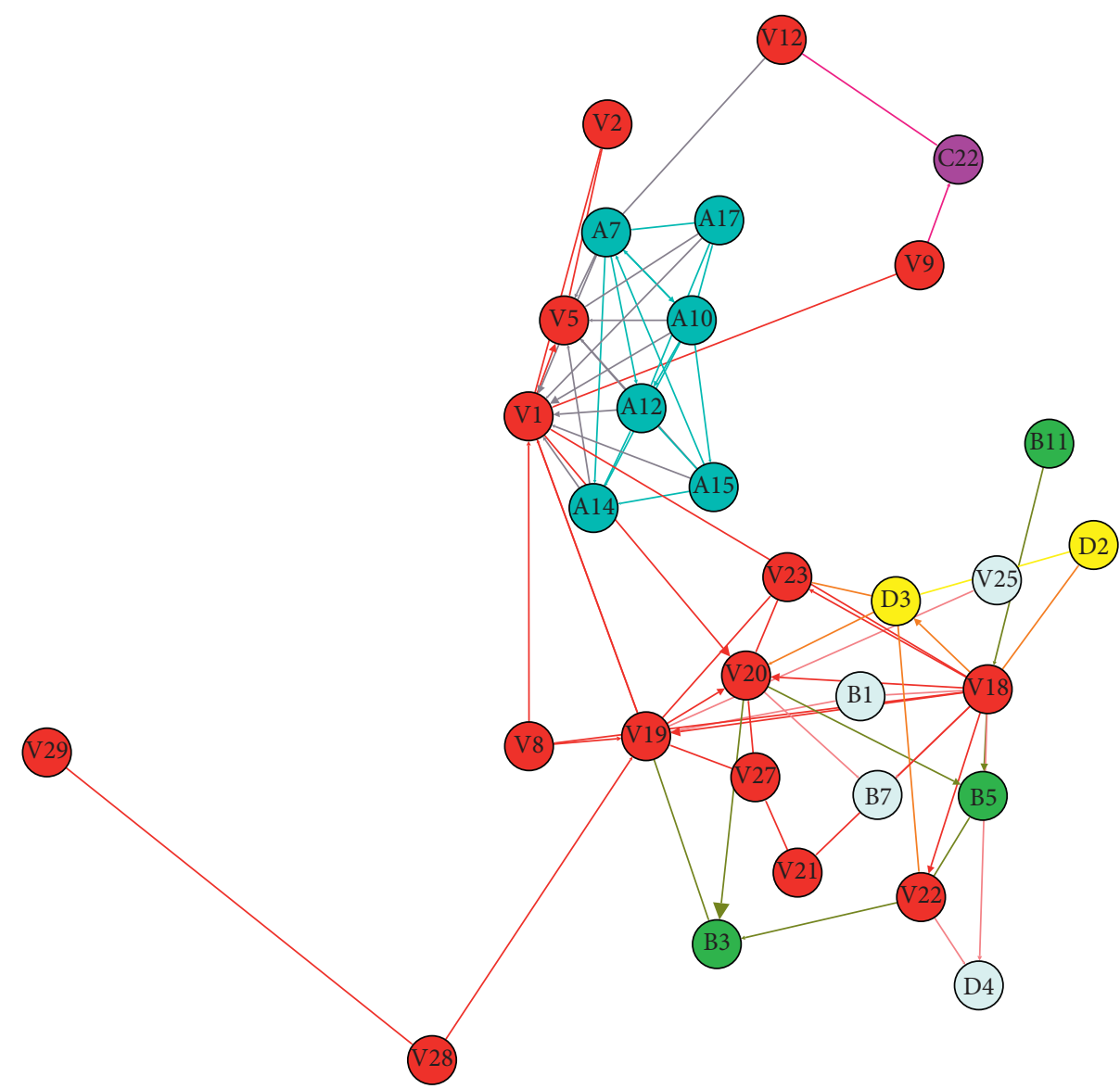

Figure 2: Complex networking graph of flight conflict in the intersecting runway. Note: only nodes with the node degree greater than or equal to 3 are retained in the figure, while nodes with the low connectivity degree are not shown in the figure.

TABle 4: Parameters of the network.

\begin{tabular}{lc}
\hline Parameter name & Value \\
\hline Number of nodes & 169 \\
Number of edges & 263 \\
Network density (directed) & 0.009 \\
Network average degree & 1.556 \\
Network average weighted degree & 20.337 \\
Network diameter & 9 \\
Network average clustering coefficient & 0.097 \\
Network average path length & 3.143 \\
\hline
\end{tabular}

and controller instruction descent $(\mathrm{C} 16)$ are all belong to the node that describes the state, not risk factors, which carry the transmission of risk factors.

Since there is no flight accident in the case set in this paper, the closeness centrality of safe landing (V20) is 1.

5.4. The Comprehensive Value of the Node. According to the relevant research results [15], the importance of nodes is determined to be described by comprehensively considering the relevant parameters. In this paper, the comprehensive value of nodes is defined as the average value of the sum of degree centrality, betweenness centrality, and closeness centrality. The importance of each node in the network is described by the comprehensive value, as shown in Table 8 .
Table 5: Distribution of nodes' degree values.

\begin{tabular}{lccccc}
\hline Number & Nodes & Degree & $\begin{array}{c}\text { Degree } \\
\text { centrality }\end{array}$ & In-degree & Out-degree \\
\hline 1 & V1 & 38 & 0.2262 & 32 & 6 \\
2 & V18 & 33 & 0.0536 & 15 & 18 \\
3 & V28 & 25 & 0.0774 & 22 & 3 \\
4 & V29 & 21 & 0.0417 & 15 & 6 \\
5 & V19 & 18 & 0.0595 & 7 & 11 \\
6 & V16 & 14 & 0.0833 & 1 & 13 \\
7 & V5 & 13 & 0.1964 & 13 & 0 \\
8 & A7 & 12 & 0.1071 & 4 & 8 \\
9 & V20 & 11 & 0.0655 & 8 & 3 \\
10 & V12 & 10 & 0.0357 & 8 & 2 \\
\hline
\end{tabular}

Note: only the top 10 nodes are shown in the table.

From the result of the comprehensive value, the case set of unsafe events adopted in this case did not cause serious consequences, so the safe landing (V20) can be eliminated. At this time, the comprehensive value of go-around flight (V2) is the largest, indicating that go-around flight is the most critical factor leading to flight conflict. Conflict relief (C22), rear cargo door warning light off (F12), suspension of subsequent take-off activities (F5), visual maintenance (C26), and other nodes have significant influences on flight conflict, and the conclusions obtained from the analysis are also consistent with the actual situation. 
TABLE 6: Betweenness centrality distribution of nodes in networks.

\begin{tabular}{lcc}
\hline Number & Nodes & Betweenness centrality \\
\hline 1 & V19 & 0.0493 \\
2 & V1 & 0.0430 \\
3 & V28 & 0.0337 \\
4 & V18 & 0.0262 \\
5 & V29 & 0.0219 \\
6 & F21 & 0.0100 \\
7 & F24 & 0.0072 \\
8 & V20 & 0.0070 \\
9 & V24 & 0.0050 \\
10 & F7 & 0.0045 \\
\hline
\end{tabular}

Note: only the top 10 nodes are shown in the table.

TABLE 7: Closeness centrality distribution of nodes in networks.

\begin{tabular}{lcc}
\hline Number & Nodes & Closeness centrality \\
\hline 1 & V2 & 1.0000 \\
2 & F5 & 1.0000 \\
3 & C3 & 1.0000 \\
4 & C7 & 1.0000 \\
5 & V20 & 1.0000 \\
6 & C12 & 1.0000 \\
7 & C16 & 1.0000 \\
8 & F12 & 1.0000 \\
9 & C20 & 1.0000 \\
10 & C22 & 1.0000 \\
11 & C26 & 1.0000 \\
12 & C33 & 1.0000 \\
\hline
\end{tabular}

TABLE 8: Comprehensive value distribution of nodes in networks.

\begin{tabular}{lcc}
\hline Number & Nodes & Comprehensive value \\
\hline 1 & V20 & 0.3575 \\
2 & V2 & 0.3512 \\
3 & C22 & 0.3454 \\
4 & F12 & 0.3385 \\
5 & F5 & 0.3375 \\
6 & C26 & 0.3374 \\
7 & C3 & 0.3373 \\
8 & C7 & 0.3373 \\
9 & C12 & 0.3373 \\
10 & C16 & 0.3373 \\
\hline
\end{tabular}

Note: only the top 10 nodes are shown in the table.

5.5. Break Chain Control Strategy. Perform scenario analysis by using a large number of cases, find the key nodes that affect the outcome of the event as well as the correlation and logic among the key nodes, and then find out the prevention and control strategies. In this paper, V2 is the most critical factor, which can effectively prevent the occurrence of flight conflict by controlling it. By controlling the risk factors that lead to resort (V2), it can reduce the occurrence or improve the safety of go-around. For the field of civil aviation, the most effective strategy includes enhancing the capability of small-scale weather forecast in the airport area, improving the conflict resolution ability of flight crews and controllers in the goaround scenario, and developing equipment to provide the capability of conflict prediction in the airport terminal area.

\section{Conclusion}

(1) In this paper, the operational risk factors of the airport with intersecting runway configuration are identified, and the visual model characteristics and key nodes of flight conflict scenario evolution of civil aircraft in the approach phase are described.

(2) The evolution network model of the flight conflict scenario of civil aircraft in the approach phase is constructed, which includes 169 nodes and 263 edges. By analyzing the parameters of the network, the risk evolution path is given and the effectiveness of the network is verified.

(3) The mechanism of flight conflict scenario evolution and propagation has not been analyzed in detail, which will be the next research focus.

\section{Data Availability}

The data used to support the findings of this study are included within the article.

\section{Conflicts of Interest}

The authors declare that they have no conflicts of interest.

\section{Acknowledgments}

This study was funded by the Safety Capacity Building Research Program of Civil Aviation Administration of China (no. ASSA2020/12) and Fundamental Research Funds for the Central Universities of Civil Aviation University of China (no. 3122018F003).

\section{References}

[1] H. Gao, X. He, and I. Zhan, "Research on the development of multi-runway airport Joperation in my country," Jiaotong Qiye Guanli, vol. 28, no. 6, pp. 60-61, 2013.

[2] Civil Aviation Administration of China, Regulations on Simultaneous Instrument Operation of Parallel Runways Order No. 123, Civil Aviation Administration of China, Beijing, China, 2004.

[3] Civil Aviation Administration of China, Civil Aviation Air Traffic Management Rules CCAR-93TM-R5, Civil Aviation Administration of China, Beijing, China, 2017.

[4] B. Yang, "Reflection on runway intrusion of Hongqiao airport," Jetliner, no. 6, pp. 75-79, 2016.

[5] J. Sun, Z. Zhang, and D. Yao, "On the handling of flight conflict from the runway incursion of Shanghai Hongqiao Airport," Technology Innovation and Application, vol. 34, no. 264, p. 292, 2016.

[6] K. Mcgarry, "Don't go there: using runway intersection lights to prevent runway incursions," Proceedings of the Human Factors and Ergonomics Society Annual Meeting, vol. 52, no. 1, pp. 16-20, 2008.

[7] M. P. ensen, I. S. Wyatt, T. L. Feyereisen, and A. Gannon, System and Method for Identifying Runway Position During an Intersection Takeoff, Honeywell International Inc., Charlotte, NC, USA, 2014.

[8] D. G. Gellert, Safe Runway Aircraft Arrival and Departure System Using Split Runway Design, USA, 2009. 
[9] Y. Yan, D. Zhu, and Q. Zhang, "Research on wake interval of intersecting runway," China Science and Technology Information, vol. 7, no. 12, pp. 43-47, 2016.

[10] D. Zhu, X. Zhou, T. Wu, and K. Chen, "Evaluation on intersecting runway capacity of Chengdu new airport based on MACAD model," Command Information System and Technology, vol. 7, no. 6, pp. 40-44, 2016.

[11] J. Wang, W. Deng, Z. Xia, and J. Wan, "Flight risk assessment method of transport aviation," China Safety Science Journal, vol. 29, no. 12, pp. 114-120, 2019.

[12] Y. Gao, X. Wang, and D. Zheng, "Research on method for predicting risk of aircraft flight conflict in airport terminal," China Safety Science Journal, vol. 1, no. 28, pp. 158-162, 2017.

[13] X. Kong, Z. Wu, and C. Yang, "Research on short-term flight conflict decision model," Science Technology and Industry, vol. 19, no. 4, pp. 112-116, 2019.

[14] Q. Wen and W. Chen, "The solving strategy of the flight conflict resolution based on the "Two-step method"” High Technology Letters, vol. 30, no. 3, pp. 268-273, 2020.

[15] X. Meng, G. Chen, C. Zheng, X. Wu, and G. Zhu, "Risk evaluation model of deepwater drilling blowout accident based on risk entropy and complex network," CIESC Journal, vol. 70, no. 1, pp. 388-397, 2019.

[16] Q. Xiao and L. Fan, "Safety risk evolution of amphibious seaplane during takeoff and landing-based on complex network," Complex Systems and Complexity Science, vol. 2, no. 3, pp. 20-30, 2019.

[17] W. Du, Research on Complex Network and Network Dynamics for Air Transportation Systems, University of Science and Technology of China, Hefei, China, 2010.

[18] J. Du, Research on Analysis and Control Problems of Airline Network Stability, Nanjing University of Aeronautics And Astronautics, Nanjing, China, 2015.

[19] Z. Zhou, Vulnerability Analysis of Civil Aviation Land-Based Air Traffic Control Maintenance System Based on Complex Network Theory, Civil Aviation Flight University of China, Deyang, China, 2018.

[20] K. Wang, Research on Traffic Congestion Identification and Control Based on Complex Network, Civil Aviation University of China, Tianjin, China, 2018.

[21] B. Ran, Study on Complex Network Model of Air Traffic Control System for PBN Operation, Civil Aviation Flight University of China, Guanghan, China, 2020.

[22] L. Tanguy, N. Tulechki, A. Urieli, E. Hermann, and C. Raynal, "Natural language processing for aviation safety reports: from classification to interactive analysis," Computers in Industry, vol. 78, pp. 80-95, 2016.

[23] M. A. Abedin, V. Ng, and L. Khan, "Cause identification from aviation safety incident reports via weakly supervised semantic lexicon construction," Journal of Artificial Intelligence Research, vol. 38, pp. 569-631, 2010.

[24] B. Xu and S. Kumar, "A text mining classification framework and its experiments using aviation datasets," in Proceedings of the Workshop of Information Technology and Systems, Dallas, TX, USA, 2015.

[25] S. Kierszbaum and L. Lapasset, "Applying distilled BERT for question answering on ASRS reports," in Proceedings of the 2020 New Trends in Civil Aviation (NTCA), pp. 33-38, Prague, Czech Republic, 2020, November.

[26] T. Liu, "Theories and methods of building major accident disaster scenarios," Fudan Public Administration Review, vol. 9, no. 2, pp. 46-55, 2013.

[27] Y. Sheng, "Study on assessment method of emergency preparedness capability based on scenario construction technology," Journal of Safety Science and Technology, vol. 10, no. 7, pp. 44-47, 2017.

[28] J. Hui, "Research on scenario expression and relationship between scenarios in real-time emergency decision," Journal of UESTC (Social Sciences Edition), vol. 14, no. 1, pp. 48-52, 2012.

[29] $2003 \mathrm{http} / / /$ news.qdu.edu.cn/news.Aspx?\%20new\%20sid=1514.

[30] X. Meng, G. Chen, and H. Zhu, "Complex network analysis on risk evolution of submarine pipeline leakage," Journal of Safety Science and Technology, vol. 13, no. 4, pp. 26-31, 2017.

[31] Z. Yao, K. Shang, and X. Xu, "Fundamental statistics of weighted networks," Journal of University of Shanghai for Science and Technology, vol. 34, no. 1, pp. 19-26, 2012. 